\title{
Penerapan Situs Bisnis dan Sosial Media Marketing pada UKM Greenfarm Makassar dalam Mendukung Program MBKM
}

\author{
Tsalis Kurniawan Husain ${ }^{1}$, Mais Ilsan ${ }^{1}$, Farizah Dhaifina Amran ${ }^{1}$, Syahrul \\ Mubarak Abdullah ${ }^{2}$ \\ ${ }^{1}$ Program Studi Agribisnis, Fakultas Pertanian, Universitas Muslim Indonesia \\ ${ }^{2}$ Program Studi Teknik Informatika, Fakultas Ilmu Komputer, Universitas Muslim \\ Indonesia \\ Email: tsalis.kurniawan@umi.ac.id, mais.ilsan@umi.ac.id, farizah.dhaifina@umi.ac.id, \\ syahrul.mubarak@umi.ac.id
}

\begin{abstract}
Greenfarm Makassar is one of the SMEs affected by Covid-19. The efforts made by Greenfarm Makassar to stay afloat during this pandemic is changing the business model from $B$ to $B$ (Business to Business) to $B$ to $C$ (Business to Consumer) by targeting the household market. The marketing strategy carried out is by re-activating Instagram social media. The problem faced by them is the lack of traffic resulting from the use of Instagram as an unpaid promotional medium, which implied in the low number of transactions. In addition, partners do not yet have an action plan in terms of order management in the $B$ to $C$ business model. The method used are data collection, creation, training on the use of business sites and paid advertising on social media. This series of activities is carried out for 1 month (December 2021). The result is that Greenfarm Makassar have an e-commerce-based business site with the address https://greenfarmmakassar.com which helps them in managing online order management from customers. In addition, they have also been able to run paid advertising on social media and resulting the increasing number of visitors and followers of their Instagram account, and increasing product demand and sales turnover.
\end{abstract}

Keywords: Greenfarm Makassar, Instagram Ads, MBKM, Situs Bisnis

\begin{abstract}
Abstrak
Greenfarm Makassar merupakan salah satu UKM yang terdampak Covid-19. Upaya yang dilakukan Greenfarm Makassar untuk tetap bertahan di masa pandemi Covid-19 yaitu mengubah bisnis model dari B to $\mathrm{B}$ (Business to Business) ke $\mathrm{B}$ to $\mathrm{C}$ (Business to Consumer) dengan menyasar segmen market rumahtangga. Strategi pemasaran yang dilakukan yaitu dengan mengaktifkan kembali sosial media Instagram. Permasalahan yang dihadapi oleh mitra adalah kurangnya traffic yang dihasilkan dari penggunaan instagram sebagai media promosi organik (tidak berbayar) sehingga berimplikasi pada rendahnya jumlah transaksi yang terjadi. Selain itu, mitra belum memiliki rencana aksi dalam hal manajemen order pada bisnis model B to C. Metode pelaksanaan kegiatan yaitu dengan pendataan, pembuatan, pelatihan penggunan situs bisnis dan iklan berbayar sosial media. Rangkaian kegiatan ini dilakukan selama 1 bulan (Desember 2021). Hasil kegiatan pengabdian ini adalah mitra telah memiliki situs bisnis berbasis e-commerce dengan
\end{abstract}


alamat situs https://greenfarmmakassar.com yang membantu mitra dalam pengelolaan manajemen order online dari pelanggan. Selain itu, mitra juga telah mampu menjalankan iklan berbayar pada sosial media (Instagram ads) sehingga jumlah kunjungan dan pengikut akun Instagram bisnis mitra meningkat. Hal ini berdampak pada meningkatnya permintaan produk dan omzet penjualan mitra.

Kata Kunci: Greenfarm Makassar, Instagram Ads, MBKM, Situs Bisnis

\section{Pendahuluan}

Program Merdeka Belajar Kampus Merdeka (MBKM) merupakan kebijakan Kemenristekdikti yang bertujuan untuk mendorong mahasiswa menguasai berbagai keilmuan yang akan bermanfaat pada dunia kerja dan dunia usaha. Mahasiswa diberikan kebebasan mengambil SKS diluar Program Studi bahkan di luar dari perguruan tinggi (Wulandari, dkk., 2021). Salah satu bentuk program MBKM yang dapat diikuti oleh mahasiswa adalah kegiatan kewirausahaan. Menurut riset dari IDN Research Institute (2019), 69\% milenial di Indonesia memiliki minat untuk berwirausaha, namun sayangnya potensi wirausaha ini belum terkelola dengan baik. Dengan adanya MBKM maka dapat memadukan keunggulan mahasiswa dalam penggunaan teknologi untuk diterapkan dalam kegiatan kewirausahaan.

Greenfarm Makassar adalah UKM yang bergerak di bidang pertanian yang memproduksi tanaman pangan dengan sistem hidroponik. Usaha ini didirikan oleh Alen Syandro pada tahun 2016 dan berlokasi di Jalan Daeng Tata 1 Blok 3, Kelurahan Parangtambung Kecamatan Tamalate, Kota Makassar. UKM ini memiliki lahan hidroponik seluas $200 \mathrm{~m}^{2}$ dengan populasi sebanyak 6.000 tanaman. Jenis tanaman yang dibudidayakan adalah selada hijau, selada merah, selada romaine, endive, kale, pakcoy, lolorosa, kangkung, sawi, mint dan bayam merah. Sistem produksi usaha ini mampu melakukan pemanenan hampir setiap hari. Pada masa sebelum Covid-19 pemesanan sering mencapai $20 \mathrm{~kg}$ per harinya, namun saat ini sulit untuk mencapai angka tersebut karena pelanggan tetap mengurangi jumlah orderannya.

Greenfarm Makassar pada masa Covid-19 dikelola oleh 5 orang terdiri dari pemilik usaha, kurir dan admin. Alen Syandro sebagai pemilik usaha melakukan hampir seluruh kegiatan operasional usaha kecuali dalam pembuatan laporan keuangan dan pengantaran orderan. Pemilik usaha ini menghandle kegiatan produksi dibantu dengan kedua orang tuanya dan kurir jika sedang tidak melakukan pengantaran pesanan. Selain itu, Pak Alen juga menghandle kegiatan pemasaran dan manajemen pesanan. Kondisi ini membuat energi pemilik usaha teralihkan untuk pekerjaan yang bersifat teknis dan rutinitas yang sejatinya pekerjaan tersebut bisa didelegasikan atau dibuatkan sistem sehingga owner bisa lebih mencurahkan energi untuk hal yang sifatnya strategis misalnya pengembangan usaha di masa ketidakpastian seperti saat ini.

Greenfarm Makassar memiliki pelanggan tetap berupa hotel, resto dan kafe yang rutin melakukan order setiap hari sehingga hampir seluruh produksi disalurkan ke pelanggan tetap dan menjadikan mereka sebagai pelanggan prioritas. Kondisi ini membuat Greenfarm Makassar memiliki ketergantungan pemasaran sehingga ketika usaha hotel, resto dan kafe terdampak Covid-19 secara langsung membuat Greenfarm Makassar mengalami penurunan pendapatan secara drastis karena secara tiba-tiba menurunnya traffic pada industri perhotelan dan restoran dine-in. 
Upaya yang dilakukan Greenfarm Makassar untuk mengatasi keadaan tersebut adalah mengubah target market, dari hotel,resto dan kafe ke market rumahtangga. Cara yang dilakukan oleh usaha hidroponik ini adalah mengaktifkan sosial media instagram yang selama ini tidak dimaksimalkan sebagai media promosi. Secara perlahan, cara ini membuat Greenfarm mulai dikenal masyarakat dan mendongkrak penjualan. Strategi mengubah target market ini memiliki tantangan bagi Greenfarm karena menjadi pemain baru untuk segmen market rumahtangga dimana kompetitor sudah terlebih dahulu menyasar segmen market ini yang telah eksis menggunakan sosial media sebelum Greenfarm Makassar. Usaha ekstra bagi Greenfarm untuk membangun brand awareness agar bisa terus eksis di masa pandemi Covid-19.

Pelanggan rumahtangga baik secara langsung maupun melalui reseller dapat melakukan pemesanan via whatsapp atau direct messages instagram. Kemudian data ini akan direkap untuk mengetahui berapa jumlah pesanan yang akan diantar pada keesokan harinya. Manajemen order ini menggunakan media grup whatsapp yang kemudian data order akan dipindahkan ke ms.excel untuk selanjutnya akan dibuatkan laporan oleh admin untuk dilaporkan dan dievaluasi sekali dalam seminggu. Manajemen order ini belum sepenuhnya mendatabase pelanggan yang telah melakukan order.

Perubahan besar yang paling dirasakan oleh Greenfarm Makassar pada masa pandemi Covid-19 adalah menurunnya omzet penjualan akibat menurunnya order dari pasar utama, yaitu hotel, resto dan kafe. Untuk tetap bertahan, strategi usaha yang dilakukan adalah menyasar segmen pasar yang baru, yaitu rumahtangga. Instagram menjadi pilihan bagi pemilik usaha untuk bisa menarik perhatian segmen pasar ini. Cara ini terbukti mampu mendongkrak penjualan dan bahkan mampu menggaet pelanggan menjadi reseller. Namun, peningkatan omzet ini belum mampu mencapai pencapaian pada masa sebelum pandemi Covid-19. Berdasarkan kondisi tersebut, permasalahan dari strategi yang dilakukan Greenfarm Makassar pada masa pandemi Covid-19 dapat diuraikan sebagai berikut:

1. Adaptasi perubahan model bisnis dari business to business (B to B) menjadi business to consumer ( $\mathrm{B}$ to $\mathrm{C}$ ). Perubahan model bisnis dengan mengubah target marketnya tentunya perlu dibarengi dengan kesiapan manajemen usaha. Jika sebelum pandemi Covid-19 usaha ini belum memiliki situs bisnis, maka dengan skema $\mathrm{B}$ to $\mathrm{C}$ pengelola usaha harus siap mengubah strategi pemasarannya dengan menafaatkan pemasaran digital.

2. Jumlah traffic yang dihasilkan dari instagram terhitung sedikit. Traffic yang ada dari penggunaan instagram sebagai media promosi organik (tidak berbayar) sangatlah bergantung dari frekuensi postingan dan pemilihan tagar/hastag pada setiap postingan. Greenfarm Makassar belum melakukan rutinitas postingan yang terjadwal (setiap hari) sehingga potensi untuk meningkatkan traffic tidak terkelola dengan baik. Per tanggal 2 Desember 2021, instagram Greenfarm (@greenfarm_makassar) hanya memiliki follower 881 orang dengan jumlah postingan sebanyak 189 post. Jumlah follower menunjukkan jumlah traffic yang berpotensi untuk melakukan transaksi pembelian. Semakin besar jumlah traffic maka semakin besar pula potensi transaksi yang terjadi. Jika ingin meningkatkan transaksi yang datang dari media sosial maka Greenfarm Makassar harus mendatangkan lebih banyak traffic dari media sosial yang digunakan. 


\section{Metode Pelaksanaan}

Metode yang digunakan adalah pelatihan, pembinaan dan evaluasi secara langsung kepada mitra. Terdapat dua macam kegiatan yang akan dilaksanakan, yaitu pembuatan situs bisnis dan pembuatan iklan di sosial media dalam hal ini Facebook dan Instagram. Kegiatan tersebut dilaksanakan selama bulan Desember 2021 di lokasi mitra yang beralamatkan di Jl. Dg. Tata I Blok No.3, Kel. Parangtambung, Kec. Tamalate, Kota Makassar melalui beberapa tahap sebagai berikut:

\section{Kegiatan I. Pembuatan Situs Bisnis \\ Tahap 1. Pendataan}

Pada tahap ini, mitra dan tim pelaksana akan duduk bersama dalam rangka melakukan pendataan terhadap semua jenis produk, harga, foto produk, gambar termasuk logo perusahaan, jumlah stok, sistem pembayaran dan sistem pengiriman produk ke konsumen, lokasi pengantaran produk. Pada tahap ini juga akan didiskusikan mengenai penentuan nama domain untuk situs bisnis

\section{Tahap 2. Pembuatan Situs Bisnis}

Setelah semua hal pada tahap I selesai, maka tahap selanjutnya yaitu pembuatan situs bisnis oleh tim pelaksana pengabdian. Pembuatan tampilan situs bisnis akan mengikuti selera mitra yang dimana telah didiskusikan pada tahap I. Situs bisnis yang akan dibuat berbasis Google My Business. Pelanggan dapat melakukan pembelanjaan secara mandiri dan setelah melakukan pemesanan,

\section{Tahap 3. Pelatihan dan Pendampingan Penggunaan Situs Bisnis}

Tahap ini berisi tentang bimbingan langsung dan pelatihan terkait pengelolaan sistem situs bisnis dari tim pelaksana kepada mitra. Hal yang terkait yaitu misalnya tata cara upload produk, memproses pembelian dari konsumen, mengedit tampilan situs bisnis, dan interaksi dengan konsumen. Tahapan bimbingan ini akan terus dilakukan hingga mitra dapat mengatasi dan menghandle sistem situs bisnis secara mandiri.

Sistem situs bisnis akan diuji terlebih dahulu apakah telah berfungsi dengan baik atau masih perlu perbaikan. Jika sistemnya telah berfungsi dengan baik maka alamat situs bisnis siap digunakan dan ditautkan dengan iklan sosial media pada kegiatan selanjutnya.

\section{Kegiatan II. Pembuatan Iklan pada Media Sosial (Social Media Marketing) Tahap I. Pendataan}

Tahap pertama pada pembuatan iklan di media sosial yaitu mendata produk best seller dan customer persona dari segmen pelanggan rumahtangga. Data ini akan diformulasikan dalam bentuk teks iklan, foto atau video, dan daftar karakteristik pelanggan, Semua data ini akan dikombinasikan pada pembuatan iklan media sosial.

\section{Tahap 2. Pembuatan Iklan}

Setelah data pada tahap I telah rampung, maka pembuatan iklan dapat dimulai. Iklan yang akan dibuat untuk tahap percobaan adalah 2-3 model iklan yang berbeda-beda selama 1-bulan. Iklan pada media sosial dapat diatur penargetan audiens berdasarkan lokasi, umur, jenis kelamin, serta interest lainnya. Audiens media sosial yang melihat iklan dari media sosial dan merasa tertarik 
dapat mengklik iklan tersebut dan secara langsung akan terhubung ke halaman situs bisnis yang telah dibuat sebelumnya, karena link situs bisnis akan dimasukkan pada iklan tersebut. Disinilah keterkaitan antara iklan dan situs bisnis yang dibuat. Selanjutnya pada halaman situs bisnis tersebut pelanggan dapat melakukan pembelanjaan secara mandiri.

\section{Tahap 3. Pelatihan dan Pendampingan Penggunaan Iklan}

Sama halnya dengan situs bisnis, mitra juga akan dilatih dan didampingi dalam pengelolaan iklan pada media sosial. Hal ini bertujuan agar mitra dapat menjadi mandiri dalam pengelolaan iklan pada media sosial.

Iklan pada media sosial ini juga secara tidak langsung dapat meningkatkan kesadaran masyarakat Makassar dan sekitarnya mengenai keberadaan produk sayuran hidroponik di perkotaan yang segar dibudidayakan secara langsung sehingga kesegaran produk bisa terjamin hingga ke konsumen.

\section{Tahap 4. Monitoring dan Evaluasi}

Setelah satu bulan berjalan, iklan dievaluasi dan kemudian diperbaiki halhal yang dianggap perlu untuk diperbaiki. Kebutuhan data untuk evaluasi ini dapat dilihat pada dashboard situs bisnis yaitu berupa interaksi pengguna situs bisnis dan iklan tersebut. Data tersebut misalnya berapa orang yang hanya melihat-lihat iklan produk, berapa orang yang hanya mengklik, berapa orang yang menyelesaikan pembelian, dan lain sebagainya. Hasil evaluasi ini dapat digunakan oleh Greenfarm untuk mengatur strategi pemasaran di masa pandemi.

\section{Hasil dan Pembahasan}

Keluaran yang dihasilkan dari kegiatan ini adalah situs bisnis berbasis ecommerce dan iklan berbayar yang dijalankan pada akun Instagram bisnis mitra. Luaran tersebut adalah sebagai berikut:

\section{Situs Bisnis Berbasis E-commerce}

Ada tiga poin utama dalam electronic commerce yaitu pertama, adanya proses baik penjualan maupun pembelian secara elektronis. Kedua, adanya konsumen atau perusahaan. Terakhir, jaringan penggunaan komputer secara online untuk melakukan transaksi bisnis (Achjari, 2000). Fungsi dari situs bisnis adalah sebagai toko online yang menyajikan berbagai produk mitra yang dapat diakses oleh calon pelanggan kapan saja dan di mana saja (Oliver, 1997). Tidak hanya sebagai etalase display produk, situs bisnis ini juga sudah dilengkapi sistem manajemen order secara online sehingga calon konsumen dapat melakukan transaksi secara mandiri, mulai dari memasukkan produk ke dalam keranjang belanja hingga menentukan metode pembayaran dan metode pengiriman. Orderan online yang masuk, selanjutnya akan diproses mitra dan mengirimkan pesanan produk ke lokasi pelanggan melalui kurir pengiriman. Alamat situs bisnis tersebut dicantumkan pada profil Instagram bisnis mitra sehingga mampu menarik pelanggan untuk mengunjungi toko online tersebut.

Manfaat yang diberikan dari penerapan ipteks ini adalah memudahkan mitra dalam melakukan manajemen order yang dilakukan secara online, manajemen stok produk, manajemen pembayaran dan pengiriman barang. Situs bisnis ini dapat menciptakan efisiensi dan efektifitas dalam operasional usaha mitra. Sejalan dengan hal ini, Rahmidani (2015) mengemukakan manfaat lain dari adanya situs bisnis bagi perusahaan adalah mendapatkan pelanggan baru, menarik konsumen untuk tetap bertahan, meningkatkan mutu layanan, dan melayani konsumen tanpa 
batas waktu. Situs bisnis mitra dapat dikunjungi pada tautan berikut https://greenfarmmakassar.com

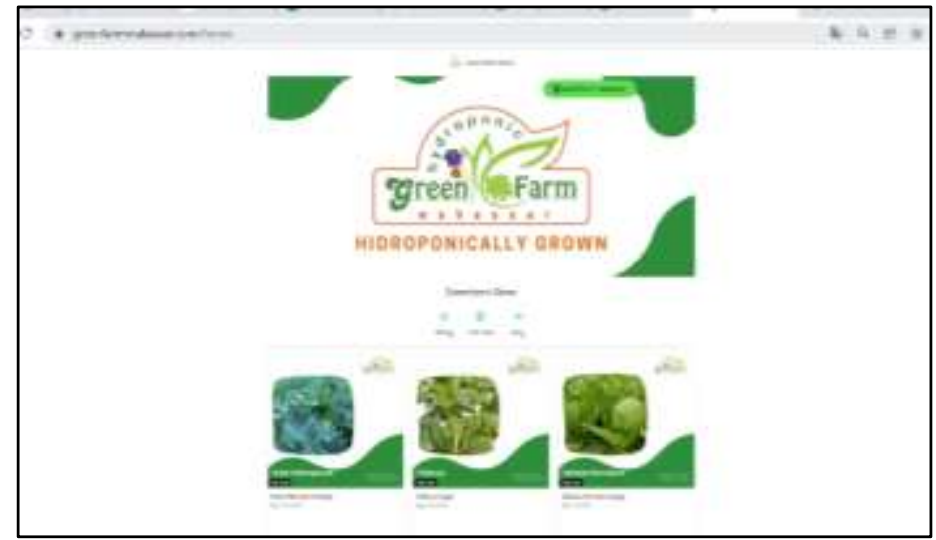

Gambar 1. Tampilan Situs Bisnis Greenfarm Makassar

\section{Iklan Berbayar pada Akun Instagram Bisnis Mitra}

Instagram yang kini menjadi konsumsi wajib mayarakat masa kini, tidak hanya sebagai media interaksi dan komunikasi tetapi sudah berkembang pada fungsi bisnis. Media online tersebut sudah bisa dijadikan media jual-beli maupun sebagai tempat beriklan (Yogantari \& Widyaswari, 2018). Untuk membuat traffic kunjungan ke sosial media mitra, maka diterapkan iklan berbayar Instagram atau yang biasa dikenal dengan istilah Instagram ads. Iklan berbayar ini dijalankan selama 1 minggu dengan varian 5 iklan. Fungsi dari penerapan ipteks ini adalah untuk memperluas jangkauan pasar mitra dengan meningkatkan jumlah kunjungan calon pelanggan ke profil Intstagram mitra. Pada profil Instagram tersebut, telah dicantumkan alamat situs bisnis mitra. Postingan iklan mitra akan ditampilkan ke lebih banyak pengguna Instagram. Semakin besar biaya iklan yang digunakan maka akan semakin besar pula jangkauan iklan mitra ditayangkan ke pengguna Instagram lainnya.

Target audiens yang tadinya hanya menerima pesan satu arah melalui iklan kini berubah posisinya sebagai pembuat konten sehingga terlibat dalam proses beriklan di media sosial sebagai pengguna. Instagram sebagai salah satu media sosial dengan angka pengguna yang tinggi menjadi pilihan yang tepat bagi sebuah merek untuk memasarkan produk mereka. Kemudahan yang disajikan oleh Instagram bagi para pengguna dalam membuat konten memberikan ruang kreatifitas yang begitu luas bagi para pelaku industri periklanan mengembangkan strategi mereka (Yogantari \& Widyaswari, 2018). Lebih lanjut, Syafitri dan Yulianto (2020) mengatakan bahwa promosi melalui iklan pada televisi dan media sosial tidak hanya sekedar untuk dapat bersaing. Melalui konten iklan dan media sosial, perusahaan dapat menyampaikan identitas merek, mengingatkan dan menyampaikan keunggulan melalui informasi yang bersifat unik, mendidik dan menarik agar konsumen dapat mengerti dan mengenal perusahaan tersebut.

Manfaat yang diperoleh dari penerapan ipteks ini adalah meningkatnya jumlah jangkauan pasar meningkatnya jumlah pengikut (follower) Instagram mitra sehingga meningkatkan kesadaran merek Greenfarm Makassar sebagai usaha yang bergerak dalam budidya sayuran hidroponik. Semakin banyak orang yang mengenali usaha mitra, maka semakin memperbesar meningkatkan potensi penjualan produk. 

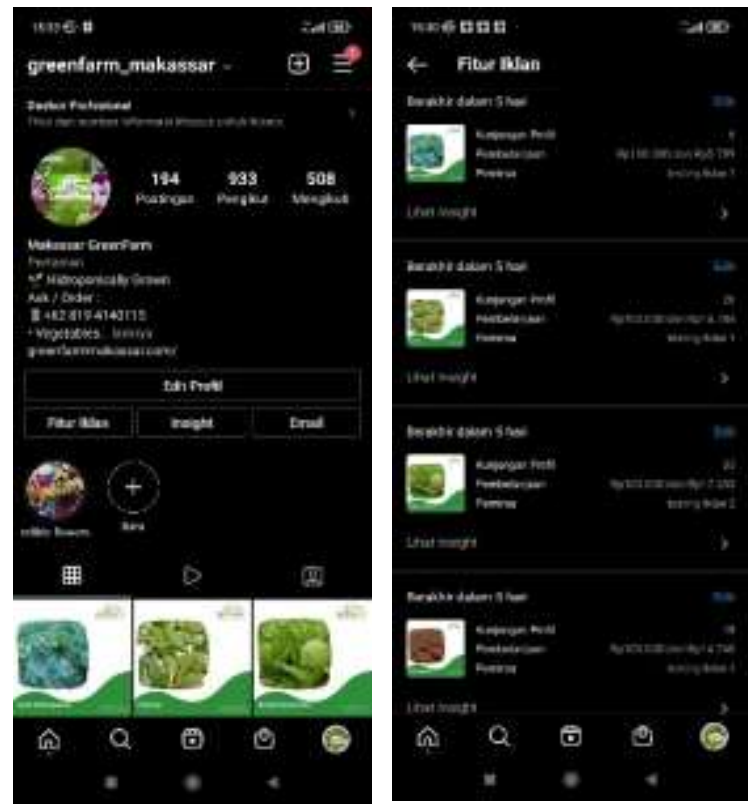

Gambar 2. Tampilan Dashboard Iklan Berbayar Instagram Greenfarm Makassar

\section{Dampak Ekonomi dan Sosial}

Dampak ekonomi dari kegiatan pengabdian ini adalah sebagai berikut:

1. Meningkatnya jangkauan pasar mitra karena penerapan iklan berbayar Instagram ads sehingga meningkatkan jumlah kunjungan pengguna Instagram ke profil Instagram bisnis mitra. Kondisi ini berdampak pada meningkatnya permintaan produk usaha mitra, sehingga meningkatkan pendapatan usahanya.

2. Efisiensi dalam pengelolaan manajemen pelanggan karena menerapkan situs bisnis berbasis e-commerce. Mitra dengan mudah melakukan pengecekan orderan, pembayaran dan pengiriman hanya melalui dashboard situs bisnis.

3. Berpotensi menyerap tenaga kerja produksi. Dengan meningkatnya jumlah permintaan produk mitra yang tidak berbanding lurus dengan ketersediaan stock produk, maka kemungkinan mitra akan mengaktifkan kembali 1 green house hidroponik miliknya.

Dampak sosial dari kegiatan pengabdian ini adalah sebagai beikut:

1. Membantu masyarakat dalam menemukan informasi makanan sehat karena makin luasnya jangkauan iklan produk mitra ke pengguna Instagram di Kota Makassar

2. Memudahkan pelanggan berinteraksi dengan mitra. Komunikasi dapat dilakukan via direct message di Instagram bisnis mitra ataupun chat whatsapp

3. memudahkan pelanggan dalam melakukan transaksi pembelian. Pelanggan dapat melakukan pembelanjaan secara online, memilih metode pembayaran dan pengiriman secara mandiri

\section{Kontribusi terhadap Sektor Lain}

Selain berdampak pada aspek ekonomi dan sosial, kegiatan ini juga berkontribusi pada sektor lainnya, seperti sebagai berikut:

1. Membantu masyarakat memiliki pola hidup sehat dengan mengkonsumsi produk bergizi, yaitu sayuran segar hidroponik.

2. Meningkatnya pengetahuan, kemampuan dan keterampilan mitra dalam pemasaran online khususnya dalam menggunakan iklan berbayar pada sosial media 
3. Meningkatnya bekal pengetahuan mahasiswa MBKM yang terlibat dalam kegiatan ini, sehingga membuat mereka lebih siap dalam perkuliahan program MBKM di semester berikutnya.

\section{Simpulan}

Berdasarkan hasil dari kegiatan PKM ini, maka dapat disimpulkan sebagai berikut:

1. Mitra telah memiliki situs bisnis berbasis e-commerce dengan alamat website https://greenfarmmakassar.com yang membantu mitra dalam manajemen order pelanggan secara online

2. Mitra telah menerapkan dan menjalankan iklan berbayar pada sosial media Instagram, sehingga iklan produk mitra memiliki jangkauan lebih luas yang berdampak pada meningkatnya permintaan produk mitra.

\section{Daftar Pustaka}

Achjari. (2000). Potensi Manfaat dan Problem di E-Commerce. Jurnal Ekonomi dan Bisnis Indonesia 2000, Vol. 15, No. 3, hal. 388 - 395.

IDN Research Institue. (2019). Indonesia Millennial Report 2019. IDN Media.

Oliver, S. (1997). A Model for The Future of Electronic Commerce. Information Management \& Computer Security Vol 5, issue 5, hal. 166-169.

Rahmidani, R. (2015). Penggunaan E-Commerce dalam Bisnis Sebagai Sumber Keunggulan Bersaing Perusahaan. Prosiding Seminar Nasional Ekonomi Manajemen dan Akuntansi (Snema) Fakultas Ekonomi Universitas Negeri Padang.

Syafitri, I., dan Yulianto, K. (2020). Pengaruh Iklan Instagram terhadap Respons Konsumen. Inter Community: Journal of Communication Empowerment | Vol. 2, No. 1, Th 2020, 31-44.

Wulandari, D., Arifin, S., Chayono, E., Kusumawardani, S. S., Wastuningsih, S. P., Soetanto, H., Utama, I. M. S., Syam, N. M., Putra, P. H., WY, H. J., Wijayanti, C., Jobih. (2021). Panduan Program Kerja Sama Kurikulum dan Implementasi Merdeka Belajar-Kampus Merdeka 2021. Direktorat Pembelajaran dan Kemahasiswaan Direktorat Jenderal Pendidikan Tinggi Kementerian Pendidikan dan Kebudayaan.

Yogantari, M. V., dan Widyaswari, I. G. A. A. W. (2018). Efektifitas Instagram sebagai Sarana Periklanan Baru di Era Digital. Prosiding Seminar Nasional Desain Sosial 2018. 